\title{
Multi-Criteria Decision Making with the VIKOR and SMARTER Methods for Optimal Seller Selection from Several E-Marketplaces
}

\author{
Miftahul Arif ${ }^{*}$, Jatmiko Endro Suseno², R. Rizal Isnanto ${ }^{3}$ \\ ${ }^{1}$ Master of Information System, Post Graduated School, Diponegoro University, Semarang, Indonesia \\ ${ }^{2}$ Department of Physics, Faculty of Science and Mathematics, Diponegoro University, Semarang, \\ Indonesia \\ ${ }^{3}$ Department of Computer Engineering, Faculty of Engineering, Diponegoro University, Semarang, \\ Indonesia
}

\begin{abstract}
Many similar products offered by several sellers in emarketplace applications make the buyers need to be more selective when shopping. This article addresses the prioritization of the goods sellers alternatives in e-marketplace by integrating the VIKOR with the SMARTER method for the process of multi-criteria decision making (MCDM) by considering various variables as selection criteria. There are five variables of sellers in the e-marketplace that are used as selection criteria, namely: product price, number of products sold, seller score rating, number of reviews with five stars, and location distance. The SMARTER method is used to determine the criteria weight, and the VIKOR model to rank the alternative priorities according to the weighted index. The case studies are conducted on three e-marketplace in Indonesia with the most number of monthly web visitors, namely: Shopee, Tokopedia, and Bukalapak. Finally, integration of SMARTER and VIKOR method allows the buyers to get the good products at competitive prices from the optimal goods sellers in the emarketplace.
\end{abstract}

Keywords. Multi-Criteria Decision Making; E-Marketplace; Seller Selection; VIKOR Method; SMARTER Method.

\section{Introduction}

The great market potential and good growth trends make e-marketplace one of the most successful digital businesses in Indonesia. This success is one of the more factors in the increasing number of choices in the e-marketplace, both in terms of application and number of sellers. Many similar products offered by several sellers in the e-marketplace applications makes the buyer must be more selective to obtain a good product at competitive prices from the optimal sellers [1]. The large, fast, and diverse number of e-marketplace data transactions

\footnotetext{
* Corresponding author: arifmiftahul@gmail.com
} 
raises big data phenomenon. Big Data analytics on e-marketplace can help companies to learn about consumer behaviour in shopping, while from the consumer side can make it easier to decide on the purchase of goods [2].

Data on e-marketplace developments in Indonesia in the fourth quarter of 2019 obtained from the site of online shopping aggregator iPrice, mentioned that Shopee has become an emarketplace with the highest number of monthly web visitors, followed by Tokopedia and Bukalapak behind it. Therefore, this paper will be focused on the selection of the optimal goods sellers from the three e-marketplace, namely: Shopee, Tokopedia, and Bukalapak.

Decision support system (DSS) to select the optimal goods seller from several emarketplace at once is a process to rank a series of alternative sellers based on several assessment criteria. Multi criteria decision making (MCDM) is the right method to solve the problem [3]. There are several alternative methods that can be used to solve MCDM problems such as AHP, ANP, ELECTRE, SMARTER, TOPSIS, PROMETHEE and VIKOR [4].

There are two kinds of approaches that can be used to help solve MCDM problems, namely: single and hybrid methods, but hybrid method approach proved more reliable, because it can cover each other's weaknesses. So, it can produce the criteria of weighted in more consistent and reliable decision making [5]. Therefore, this study will use a hybrid approach by combining the SMARTER and VIKOR methods.

The VIKOR method (Vlse Kriterijumska Optimizacija Kompromisno Resenje) has been widely used to solve various decision-making issues based on multi-criteria [6]. This method focuses on the selection and ranking of several alternatives with conflicting criteria [7] by proposing a compromise solution to the results based on the estimated ideal solution [8]. The VIKOR method has weaknesses in the initial weighting process of criteria that is subjective, so a combination with other methods is needed to obtain more accurate and more stable results [5]. To cover it, this study will be combined with the SMARTER method (Simple Multi-Attribute Rating Technique Exploiting Ranks). This method determines the weight of each criterion based on ROC (Rank Order Centroid) calculations [9], which has been widely applied to the multi-criteria model, because it has proven advantages in the process of weighting criteria, so that the results of the consistency of distance between criteria can be maintained [10]. As an example the study of Hidayat et al. [11] which has proven that modification of the weighting of criteria by the SMARTER method has proven to be more selective in determining scholarship recipients.

Some related studies are the main references for this study, because they have similar topics and purposes, namely: the development of information systems to help select the optimal goods sellers on AliExpress using the AHP method [1], and the development of an optimal seller recommendation system in the e-marketplace using the Simple Additive Weighting (SAW) method [12]. This study aims to combine the VIKOR and SMARTER method to provide recommendations for the optimal goods sellers from three e-marketplaces at once automatically, namely: Shopee, Tokopedia, and Bukalapak. So, buyers will get products at competitive prices, and various other criteria that are taken into consideration. There are five seller variables that will be used as selection criteria, namely: product price, number of products sold, seller score rating, number of reviews with five stars, and location distance.

\section{Materials and Methods}

\subsection{Materials}

This study uses web mining techniques with scraping tool, as shown in Fig 1. to mine data from three e-marketplaces in Indonesia, namely: Shopee, Tokopedia, and Bukalapak which 
contain products, sellers, and attributes selected as criteria [13]. The selection of these attributes is based on previous study [12], and sourced from field research by surveys and interviews with a number of respondents who are experienced and still actively transacting in the e-marketplace. The seller attributes selected as consideration in the selection, there are five kinds of criteria, as shown in Table 1.

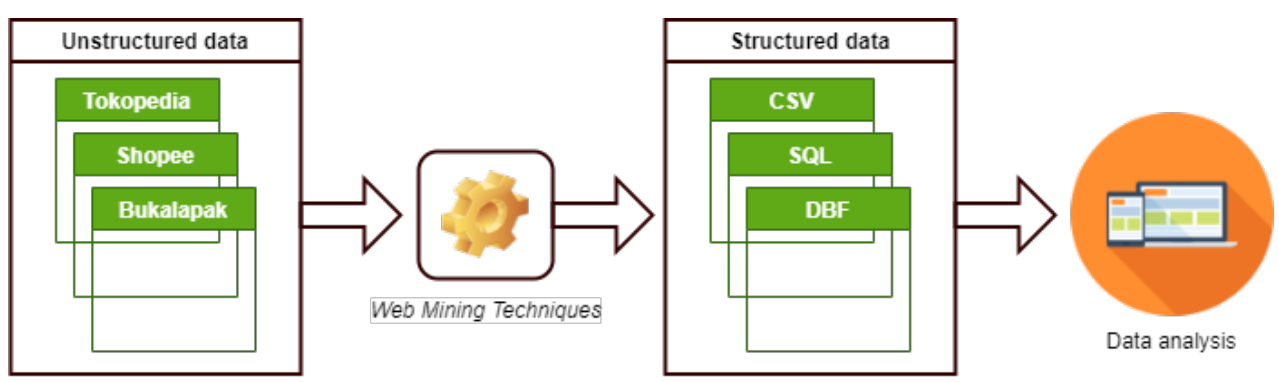

Fig 1. Schema of data mining process from three e-marketplaces

Table 1. The DSS criteria

\begin{tabular}{|c|c|c|}
\hline No & Criteria & Criteria Description \\
\hline 1 & Seller Score Rating & $\begin{array}{l}\text { - Seller ratings based on buyer ratings } \\
\text { - Higher-the-better (Benefit) }\end{array}$ \\
\hline 2 & $\begin{array}{l}\text { Number of Reviews } \\
\text { with } 5 \text { Stars }\end{array}$ & $\begin{array}{l}\text { - Buyer reviews with } 5 \text { stars show the seller's } \\
\text { performance is very positive } \\
\text { - Higher-the-better (Benefit) }\end{array}$ \\
\hline 3 & Product Price & $\begin{array}{l}\text { - Identified by the nominal in Rupiah currency (IDR) } \\
\text { - Lower-the-better (Cost) }\end{array}$ \\
\hline 4 & $\begin{array}{l}\text { Number of Products } \\
\text { Sold }\end{array}$ & $\begin{array}{l}\text { - Number of products successfully sold } \\
\text { - Higher-the-better (Benefit) }\end{array}$ \\
\hline 5 & Location Distance & $\begin{array}{l}\text { - Distance between seller and buyer location in KM units } \\
\text { - Lower-the-better (Cost) }\end{array}$ \\
\hline
\end{tabular}

\subsection{Methods}

Reference in multi-criteria decision making (MCDM) is how we can make a decision based on several conflicting criteria. The decision maker must be able to choose the most appropriate alternative from a number of alternatives, based on pre-defined selection criteria [6]. MCDM is a practical and reliable tool in solving problems that are certain or not, and can facilitate the merging of quantitative and qualitative methods of scientific analysis [14]. This study will implement the VIKOR and SMARTER methods to help select and determine the optimal goods seller ranking from three e-marketplaces at once.

The VIKOR method is a decision making technique developed to optimize multi-criteria problems [15]. Several studies on the implementation of the VIKOR method in MCDM have been carried out, such as the suppliers selection in the nuclear power industry [16], material selection for the repair of concrete structures [17], weapon system selection based on consistency analysis [18], and the ranking of concrete bridge repair projects with target-based criteria [7]. From various studies it can be concluded that the VIKOR method is proven to help the selection and ranking process on MCDM issues. The basic concept of the VIKOR method is to determine the alternative ranking based on the results of the regret $(R)$ value of each alternative. The core of this method is how to select and then rank the results it in the form of alternative sets with conflicting criteria [19]. 
The following is a sequence of steps from the proposed method, namely implementing the VIKOR and SMARTER methods to determine the optimal goods seller rank from three e-marketplaces [18, 20, 21, 22] :

Step 1 : Define the decision-making criteria.

The first step is to define the criteria used to make decisions, there are five seller attributes selected as consideration in the selection, as shown in Table 1.

Step 2 : Create a decision matrix $(F)$ based on existing alternatives and criteria.

In this step each alternatives and criterion is arranged in the form of a Decision matrix $(F)$, $A_{i}$ declared $i^{\text {th }}$ alternative $i=1,2,3, \ldots, n ; C_{x n}$ declared $j^{t h}$ criteria $j=1,2,3, \ldots, m . x_{i j}$ is the alternative response $i$ in the criteria $j$.

$$
F=\frac{A_{1}}{A_{2}}\left[\begin{array}{cccc}
C_{x 1} & C_{x 2} & \cdots & C_{x n} \\
x_{11} & x_{12} & \cdots & x_{1 n} \\
A_{m} & x_{22} & \cdots & x_{2 n} \\
\vdots & \vdots & \ddots & \vdots \\
x_{m 1} & x_{m 2} & \cdots & x_{m n}
\end{array}\right]
$$

Step 3 : Determine the weights for each criterion

Determine the weight of each criterion $(W)$ based on the level of importance using the SMARTER method. This method is based on the theory that each alternative has a number of criteria that contain values, in addition each of these criteria has a weighted describing the importance level compared to other criteria. Determination of priority criteria is usually formed with the statement "criterion 1 is more important than criterion 2, which is more important than criterion 3 and so on until criterion $j$ ", or can be written $C_{1} \geq C_{2} \geq C_{3} \geq \ldots \geq C_{i}$, to determine its weight can be explained as the following equation [23].

$$
W_{1} \geq W_{2} \geq W_{3} \geq \ldots . . W_{j}
$$

Weighting with the ROC technique, can be formulated as follows:

$$
W_{j}=\left(\frac{1}{J}\right) \sum_{i=j}^{J}\left(\frac{1}{i}\right)
$$

where $J$ expressed as the number of criteria, $j$ as $j$-th criterion, and $i$ expressed as order of criteria $(i=1,2,3, \ldots, j)$.

Step 4 : Normalize the matrix

Make a normalized matrix by determining positive $\left(f_{j}^{*}\right)$ and negative $\left(f_{j}^{-}\right)$values as the ideal solution for each criterion, as the following equation:

- If the criteria are in the benefit category, then use the function:

$$
f_{j}^{*}=\max _{j} f_{i j} \text { and } f_{j}^{-}=\min _{j} f_{i j}
$$

- If the criteria are in the cost category, then use the function:

$$
f_{j}^{*}=\min _{j} f_{i j} \text { and } f_{j}^{-}=\max _{j} f_{i j}
$$

where $i$ expressed as order of alternative $(i=1,2,3, \ldots, n)$, and $j$ expressed as order of criteria $(j=1,2,3, \ldots, m)$.

Step 5 : Calculate the utility measure $(S)$ and regret measures $(R)$ of each alternative. 


$$
\begin{aligned}
& S_{i}=\sum_{j=1}^{n} W_{j} \frac{\left(f^{*}-f_{i j}\right)}{\left(f_{j}^{*}-f_{j}^{-}\right)} \\
& R_{i}=\max _{j}\left[W_{j} \frac{\left(f^{*}-f_{i j}\right)}{\left(f_{j}^{*}-f_{j}^{-}\right)}\right]
\end{aligned}
$$

Where $S_{i}$ expressed as the value of the alternative distance to the positive ideal solution, $R_{i}$ is the value of the alternative distance to the negative ideal solution, and $W_{j}$ is the weight value obtained from calculations with the SMARTER method (step 3).

Step 6 : Calculate the value of VIKOR index

$$
Q_{i}=v\left[\frac{\left(S_{i}-S^{*}\right)}{\left(S^{*}-S^{-}\right)}\right]+(1-v)\left[\frac{\left(R_{i}-R^{*}\right)}{\left(R^{*}-R^{-}\right)}\right]
$$

Where $S^{*}$ is $\max _{i}\left(S_{i}\right), S^{-}$for $\min _{i}\left(S_{i}\right), R^{*}$ is $\max _{i}\left(R_{i}\right)$, and $R^{-}$as $\min _{i}\left(R_{i}\right)$, and $v$ was weight ranging from 0 to 1 (generally 0.5 ). The smaller VIKOR index $\left(Q_{i}\right)$, the better of alternative solution.

Step 7 : Rank the alternatives.

After $Q_{i}$ was calculated (step 6), there would be three types of ranking: $S_{i}, R_{i}$, and $Q_{i}$. Compromise solutions were seen in $Q_{i}$ ranking.

Step 8 : Propose as a compromise solution.

Finally, the last step measures the minimum VIKOR index based on the following conditions:

1) Condition 1 : Acceptable advantage, a difference between the $Q_{A 1}$ and $Q_{A 2}$, the best and the second alternative ranking respectively.

$$
\begin{aligned}
& Q_{A 2}-Q_{A 1} \geq D Q \\
& \text { Where } D Q=\frac{1}{(m-1)}
\end{aligned}
$$

where $m$ is the number of alternatives.

2) Condition 2 : Acceptable stability in decision making. This compromise solution is stable in the decision-making process that could be due to: "vote by majority rule" (when $v>$ $0.5)$, or "by consensus" ( $v=0.5)$, or "by veto" $(v<0.5)$.

If any of conditions is not satisfied, a compromise solution can be proposed as follows:

- Alternative $Q_{A 1}$ and $Q_{A 2}$, if only Acceptable stability condition in decision making is not satisfied.

- Chooses alternative $Q_{A 1}, Q_{A 2}, \ldots, Q_{A m}$, if Acceptable Advantage condition is not satisfied; $Q_{A m}$ is the alternative determined from the relation.

$$
Q_{(A m)}-Q_{(A 1)}<D Q
$$

Where $m$ maximum is an alternative which the position are "in closeness". 


\section{Implementation}

The implementation of the SMARTER method usually involves respondents who have competence as decision makers to determine the priority level of each criterion needed in the SMARTER method for ROC calculations. So, in this study uses a multilevel (Likert scale) questionnaire on each answer given to respondents who are experienced and still actively transacting in the e-marketplace to determine it. The results are as shown in Table 2.

Table 2. The Weight value of each criterion

\begin{tabular}{lcccc}
\hline Criteria Name & Code & Category & $\begin{array}{c}\text { Priority } \\
\text { Level }\end{array}$ & $\begin{array}{c}\text { Criteria Weights }\left(W_{j}\right) \\
\text { using ROC }\end{array}$ \\
\hline Seller Score Rating & C1 & Benefit & 1 & 0,46 \\
Number of Reviews with 5 Stars & C2 & Benefit & 2 & 0,26 \\
Product Price & C3 & Cost & 3 & 0,16 \\
Number of Products Sold & C4 & Benefit & 4 & 0,09 \\
Location Distance & C5 & Cost & 5 & 0,04 \\
\hline
\end{tabular}

The system will be built using 2 kinds of data as input. Firstly, data from users in the form of price restrictions, destination addresses, and product search keywords. Secondly, the system will mine the seller data from the e-marketplace based on the user input that contains several attributes, namely: product price, number of products sold, seller rating rating, number of reviews with five stars, and the seller's address. The system will automatically calculate the user's location distance with the seller by utilizing the Google Maps service. Google Maps is one of the most powerful mapping application services created by Google, which features an API key enabling developers to integrate these mapping services into systems [24]. The analysis process flow, as shown in Fig. 2.

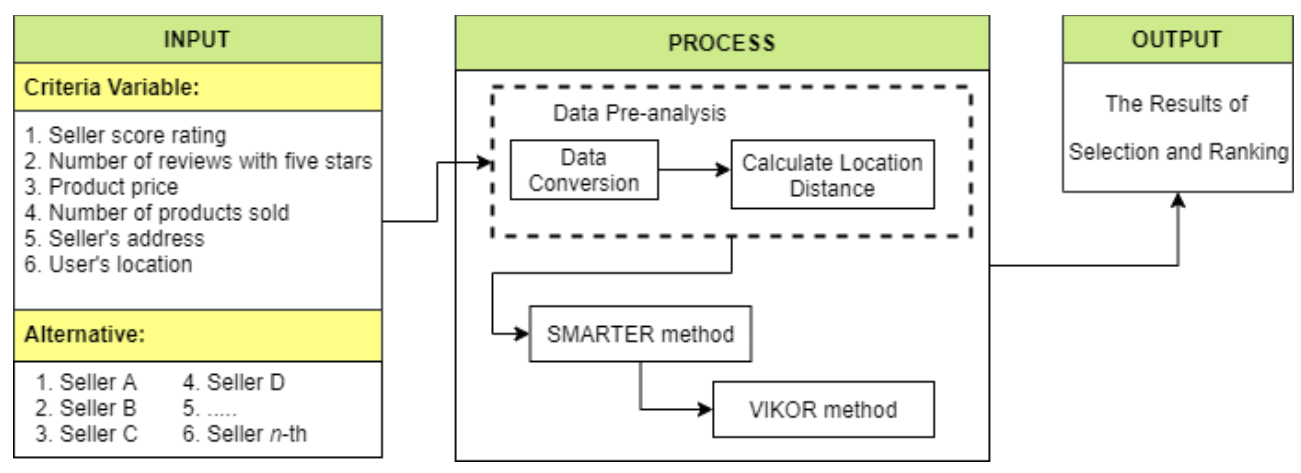

Fig 2. Analysis process flow

Data samples based on search results from Shopee, Tokopedia, and Bukalapak with the keyword "Samsung a10" taken on April 27, 2020. Then, we selected 15 alternative sellers based on price with the destination address Semarang city as an example of a case analysis in this study, as shown in Table 3. Then, the data is calculated using the proposed method, so as to generate the conclusions as shown in Table 4 and Table 5. 
Table 3. Criteria information of selected seller from e-marketplaces

\begin{tabular}{clclrrrr}
\hline Marketplace & \multicolumn{1}{c}{ Seller's Name } & Code & \multicolumn{1}{c}{ Location } & C1 & C2 & C3 & \multicolumn{1}{c}{ C4 } \\
\hline Tokopedia & one's_olshop & A1 & Kab. Bogor & 4,9 & 76 & 1.604 .000 & 1.093 \\
Tokopedia & Distributor Ponsel & A2 & Jakarta barat & 4,7 & 276 & 1.636 .000 & 2.207 \\
Tokopedia & varelie ponsel & A3 & Jakarta barat & 5,0 & 110 & 1.665 .000 & 484 \\
Tokopedia & Barokah Online Abadi & A4 & Demak & 4,8 & 64 & 1.625 .000 & 207 \\
Tokopedia & HN Store 2003 & A5 & Jakarta Pusat & 5,0 & 40 & 1.620 .000 & 607 \\
Shopee & quenzyqee & A6 & Kab. Tangerang & 4,9 & 93 & 1.600 .000 & 453 \\
Shopee & murah2019 & A7 & Tangerang Selatan & 4,9 & 9 & 1.609 .999 & 62 \\
Shopee & nashop7979 & A8 & Jakarta Selatan & 4,9 & 39 & 1.610 .000 & 70 \\
Shopee & hnstore2003 & A9 & Jakarta Pusat & 4,8 & 8 & 1.620 .000 & 13 \\
Shopee & shopeedia & A10 & Jakarta barat & 4,7 & 6 & 1.675 .000 & 20 \\
Bukalapak & JAYA STORE & A11 & Jakarta Utara & 4,7 & 16 & 1.674 .000 & 41 \\
Bukalapak & Xiaomi Store & A12 & Jakarta Pusat & 4,2 & 1 & 1.673 .070 & 8 \\
Bukalapak & Gojap & A13 & Jakarta barat & 4,8 & 95 & 1.675 .000 & 438 \\
Bukalapak & Dsun Shop & A14 & Kab. Bogor & 5,0 & 9 & 1.625 .000 & 13 \\
Bukalapak & Metta Cell Bekasi & A15 & Bekasi & 5,0 & 5 & 1.670 .000 & 14 \\
\hline
\end{tabular}

Table 4. Implementation procedure for the proposed method steps 1-3

\begin{tabular}{|c|c|c|c|c|c|}
\hline Alternatives & $\mathrm{C} 1$ & $\mathrm{C} 2$ & $\mathrm{C} 3$ & $\mathrm{C} 4$ & C5 \\
\hline A1 & 4,9 & 76 & 1.604 .000 & 1.093 & 480 \\
\hline A2 & 4,7 & 276 & 1.636 .000 & 2.207 & 452 \\
\hline A3 & 5,0 & 110 & 1.665 .000 & 484 & 452 \\
\hline A4 & 4,8 & 64 & 1.625 .000 & 207 & 34 \\
\hline A5 & 5,0 & 40 & 1.620 .000 & 607 & 446 \\
\hline A6 & 4,9 & 93 & 1.600 .000 & 453 & 485 \\
\hline A7 & 4,9 & 9 & 1.609 .999 & 62 & 463 \\
\hline A8 & 4,9 & 39 & 1.610 .000 & 70 & 405 \\
\hline A9 & 4,8 & 8 & 1.620 .000 & 13 & 446 \\
\hline A 10 & 4,7 & 6 & 1.675 .000 & 20 & 452 \\
\hline A11 & 4,7 & 16 & 1.674 .000 & 41 & 444 \\
\hline A12 & 4,2 & 1 & 1.673 .070 & 8 & 446 \\
\hline A13 & 4,8 & 95 & 1.675 .000 & 438 & 452 \\
\hline A 14 & 5,0 & 9 & 1.625 .000 & 13 & 480 \\
\hline A 15 & 5,0 & 5 & 1.670 .000 & 14 & 424 \\
\hline$W_{j}$ & 0,09 & 0,04 & 0,46 & 0,16 & 0,26 \\
\hline$f_{j}^{*}$ & 5,0 & 276 & 1.600 .000 & 2.207 & 34 \\
\hline$f_{j}^{-}$ & 4,2 & 1 & 1.675 .000 & 8 & 485 \\
\hline
\end{tabular}

Table 5. Implementation procedure for the proposed method steps 4-7

\begin{tabular}{|c|c|c|c|c|c|c|c|c|c|}
\hline Alternatives & $\mathrm{C} 1$ & $\mathrm{C} 2$ & $\mathrm{C} 3$ & $\mathrm{C} 4$ & C5 & $S_{i}$ & $\boldsymbol{R}_{i}$ & $Q_{i}$ & Rank \\
\hline $\mathrm{A} 2$ & 0,1713 & 0,0000 & 0,0752 & 0,0000 & 0,0371 & 0,2835 & 0,1713 & 0,0270 & 1 \\
\hline $\mathrm{A} 4$ & 0,1142 & 0,1979 & 0,0522 & 0,0819 & 0,0000 & 0,4461 & 0,1979 & 0,1858 & 6 \\
\hline A5 & 0,0000 & 0,2203 & 0,0418 & 0,0655 & 0,0365 & 0,3641 & 0,2203 & 0,1651 & 5 \\
\hline A6 & 0,0571 & 0,1708 & 0,0000 & 0,0718 & 0,0400 & 0,3397 & 0,1708 & 0,0659 & 2 \\
\hline A8 & 0,0571 & 0,2212 & 0,0209 & 0,0875 & 0,0329 & 0,4195 & 0,2212 & 0,2057 & 7 \\
\hline A9 & 0,1142 & 0,2501 & 0,0418 & 0,0898 & 0,0365 & 0,5324 & 0,2501 & 0,3333 & 12 \\
\hline A10 & 0,1713 & 0,2520 & 0,1567 & 0,0895 & 0,0371 & 0,7065 & 0,2520 & 0,4591 & 14 \\
\hline A11 & 0,1713 & 0,2427 & 0,1546 & 0,0886 & 0,0364 & 0,6935 & 0,2427 & 0,4345 & 13 \\
\hline A 12 & 0,4567 & 0,2567 & 0,1526 & 0,0900 & 0,0365 & 0,9925 & 0,4567 & 1,0000 & 15 \\
\hline A 13 & 0,1142 & 0,1689 & 0,1567 & 0,0724 & 0,0371 & 0,5492 & 0,1689 & 0,2106 & 8 \\
\hline \multirow{2}{*}{ Category } & & & & & $S^{*} ; R^{*}$ & 0,2835 & 0,1549 & & \\
\hline & & & & & $S^{-} ; R^{-}$ & 0,9925 & 0,4567 & & \\
\hline
\end{tabular}




\section{Result and Discussion}

A compromise solution is determined from the alternative that has the best ranked by the measure $Q$ (minimum), if the following two conditions are satisfied:

1) Condition $1:$ Acceptable advantage

$$
\begin{gathered}
D Q=\frac{1}{(m-1)}=\frac{1}{(15-1)}=\frac{1}{14}=0,0714 \\
Q_{A 6}-Q_{A 2}=0,0659-0,0270=0,0389
\end{gathered}
$$

The value of $Q_{A 6}-Q_{A 2}<D Q$. So, Acceptable advantage conditions are not satisfied.

2) Condition 2 : Acceptable stability in decision making

The best ranking results $\left(Q_{i}\right)$ with consistently different $v$ values are Alternative 2 (A2) $(v=0,45 ; v=0,5$; and $v=0,55)$, as shown in Table 6 . So, it can be proved that the condition Acceptable stability in decision making is satisfied.

\begin{tabular}{|c|c|c|c|c|c|c|c|c|c|c|c|c|c|c|c|}
\hline $\operatorname{Rank}\left(\boldsymbol{Q}_{i}\right)$ & A1 & A2 & A3 & A4 & A5 & A6 & A7 & A8 & A9 & A10 & A11 & A12 & A13 & A14 & A15 \\
\hline$v=0,5$ & 4 & 1 & 3 & 6 & 5 & 2 & 10 & 7 & 12 & 14 & 13 & 15 & 8 & 9 & 11 \\
\hline $\begin{array}{l}v \\
=0,45\end{array}$ & 4 & 1 & 3 & 6 & 5 & 2 & 10 & 8 & 12 & 14 & 13 & 15 & 7 & 9 & 11 \\
\hline $\begin{array}{l}v \\
=0,55\end{array}$ & 3 & 1 & 4 & 6 & 5 & 2 & 10 & 7 & 12 & 14 & 13 & 15 & 8 & 9 & 11 \\
\hline
\end{tabular}

Table 6. Ranking of $Q_{i}$ with different value of $v$

From this explanation, it can be seen that condition 1: Acceptable advantage is not satisfied, therefore we choose alternative $Q_{A 6}, Q_{A 3}$, and $Q_{A 1}$ which the position are "in closeness" with $Q_{A 2}$, as shown in Table 7 .

Table 7. Rank the alternatives

\begin{tabular}{ccccccccc}
\hline $\boldsymbol{Q}_{\boldsymbol{A m}}$ & $\boldsymbol{Q}_{\boldsymbol{A} \mathbf{2}}$ & $\boldsymbol{Q}_{\boldsymbol{A} \mathbf{6}}$ & $\boldsymbol{Q}_{\boldsymbol{A} \mathbf{3}}$ & $\boldsymbol{Q}_{\boldsymbol{A} \mathbf{1}}$ & $\boldsymbol{Q}_{\boldsymbol{A} \mathbf{5}}$ & $\boldsymbol{Q}_{\boldsymbol{A 4}}$ & $\ldots$ & $\boldsymbol{Q}_{\boldsymbol{A 1 2}}$ \\
\hline $\operatorname{Rank}\left(\boldsymbol{Q}_{\boldsymbol{i}}\right)$ & 1 & 2 & 3 & 4 & 5 & 6 & & 15 \\
\hline $\boldsymbol{v}=\mathbf{0 , 5}$ & 0,0270 & 0,0659 & 0,0809 & 0,0905 & 0,1651 & 0,1858 & $\ldots$ & 1,0000 \\
\hline
\end{tabular}

$$
\begin{gathered}
D Q=\frac{1}{(m-1)}=\frac{1}{(15-1)}=\frac{1}{14}=0,0714 \\
Q_{A 6}-Q_{A 2}=0,0659-0,0270=0,0389<0,0714 \\
Q_{A 3}-Q_{A 2}=0,0809-0,0270=0,0539<0,0714 \\
Q_{A 1}-Q_{A 2}=0,0905-0,0270=0,0634<0,0714
\end{gathered}
$$

From these calculations it can be seen, that $Q_{A 2}$ is not superior to $Q_{A 6}, Q_{A 3}$, and $Q_{A 1}$. So, four of them all, namely: $Q_{A 2}, Q_{A 6}, Q_{A 3}$, and $Q_{A 1}$ can all be considered as compromise solution of Samsung A10 product sellers ranking from three e-marketplaces with the SMARTER and VIKOR method at the time of data collection.

\section{Conclusions}


Optimal seller selection and ranking from several e-marketplaces is one of the case of multicriteria decision making issues. The process involves data that contains numerous seller alternatives as an option with multiple conflicting criteria. Therefore, a decision support system is needed that can help it. This study proposes a combination of the VIKOR and SMARTER methods as a solution to the problem, because from various previous studies, the VIKOR method proved to help solve the problem of selection and ranking of a number of alternatives that have conflicting criteria. Meanwhile, the SMARTER method has an advantage in the initial weighting of criteria by using ROC calculations, so that this combination can cover the weaknesses of each.

This study takes an example of the Samsung A10 seller selection process from three emarketplaces, namely: Shopee, Tokopedia and Bukalapak in the form of sample data containing 15 alternative sellers along with five selection criteria. The combination of the SMARTER and VIKOR methods helps provide optimal seller recommendations by giving the best ranking results $\left(Q_{i}\right)$ with $v=0,5$, namely : Distributor Ponsel $(\mathrm{A} 2)=0,0270$, quenzyqee $(\mathrm{A} 6)=0,0659$, varelie ponsel $(\mathrm{A} 3)=0,0809$, one's_olshop $(\mathrm{A} 1)=0,0905$.

\section{Acknowledgement}

The research and preparation of this paper was successful thanks to the exceptional support and assistance from various parties. The author would like to thanks the PasTi Scholarship Program, from the Ministry of Research, Technology and Higher Education, Republic of Indonesia, for providing this research funding assistance. Jatmiko Endro Suseno and R. Rizal Isnanto, Lecturers of Master of Information System, Post Graduated School, Diponegoro University, who have guided and examined my research transcript. And all those who have supported and assisted my research.

\section{References}

1. V. Shendryk, D. Bychko, Y. Parfenenko, O. Boiko, and N. Ivashova, "Information system for selection the optimal goods supplier," Procedia Comput. Sci., 149, pp. 5764 (2019).

2. S. Akter and S. F. Wamba, "Big data analytics in E-commerce: a systematic review and agenda for future research," Electron. Mark., 26, no. 2, pp. 173-194 (2016).

3. M. Mohammadi and J. Rezaei, "Ensemble Ranking: Aggregation of rankings produced by different multi-criteria decision-making methods," Omega, p. 102254 (2020).

4. F. C. N. Piengang, Y. Beauregard, and J. P. Kenné, "An APS software selection methodology integrating experts and decisions-maker's opinions on selection criteria: A case study," Cogent Eng., 6, no. 1, pp. 1-34 (2019).

5. A. P. Wibawa, J. A. Fauzi, S. Isbiyantoro, R. Irsyada, Dhaniyar, and L. Hernández, "VIKOR multi-criteria decision making with AHP reliable weighting for article acceptance recommendation," Int. J. Adv. Intell. Informatics, 5, no. 2, pp. 160-168 (2019).

6. P. Wang, Z. Zhu, and Y. Wang, "A novel hybrid MCDM model combining the SAW, TOPSIS and GRA methods based on experimental design," Inf. Sci. (Ny)., 345, pp. 2745 (2016).

7. Z. Gao, R. Y. Liang, and T. Xuan, "VIKOR method for ranking concrete bridge repair projects with target-based criteria," Results Eng., 3, no. April, p. 100018 (2019).

8. S. Opricovic and G. H. Tzeng, "Compromise solution by MCDM methods: A comparative analysis of VIKOR and TOPSIS," Eur. J. Oper. Res., 156, no. 2, pp. 445455 (2004). 
9. Rasim, E. F. Rahman, N. F. Dewi, and L. S. Riza, "Decision Support Systems for Performance and Evaluation of Teachers in General-English Course by Using the SMARTER and TOPSIS Methods," IOP Conf. Ser. Mater. Sci. Eng., 180, no. 1, p. 012283 (2017).

10. D. Karyaningsih and A. Wibowo, "The Support System Decision the Determination of Poor Community Welfare with the Methods Web-Based SMARTER: Case Studies Regency Lebak the Province of Banten," J. Phys. Conf. Ser., 1179, no. 1 (2019).

11. S. Hidayat, Tulus, and P. Sirait, "Weighting Optimization of Decision Matrix in Fuzzy TOPSIS Using SMARTER Method,” J. Phys. Conf. Ser., 1235, no. 1 (2019).

12. M. M. Mardhia and D. Normawati, "Marketplace seller recommender with user-based multi criteria decision making," Proceeding 2018 12th Int. Conf. Telecommun. Syst. Serv. Appl. TSSA 2018, pp. 1-5 (2018).

13. Fatmasari, Y. N. Kunang, and S. D. Purnamasari, "Web Scraping Techniques to Collect Weather Data in South Sumatera," Proc. 2018 Int. Conf. Electr. Eng. Comput. Sci. ICECOS 2018, no. December, pp. 385-390 (2019).

14. F. Sitorus, J. J. Cilliers, and P. R. Brito-Parada, "Multi-criteria decision making for the choice problem in mining and mineral processing: Applications and trends," Expert Syst. Appl., 121, pp. 393-417 (2019).

15. J. Wang, G. Wei, and M. Lu, “An extended VIKOR method for multiple criteria group decision making with triangular fuzzy neutrosophic numbers," Symmetry (Basel)., 10, no. 10 (2018).

16. Y. Wu, K. Chen, B. Zeng, H. Xu, and Y. Yang, "Supplier selection in nuclear power industry with extended VIKOR method under linguistic information," Appl. Soft Comput. J., 48, pp. 444-457 (2016).

17. B. Kiani, R. Y. Liang, and J. Gross, "Material selection for repair of structural concrete using VIKOR method," Case Stud. Constr. Mater., 8, no. January, pp. 489-497 (2018).

18. X. Zhang, J. Jiang, B. Ge, and K. Yang, "Group decision making for weapon systems selection with VIKOR based on consistency analysis," 10th Annu. Int. Syst. Conf. SysCon 2016 - Proc., (2016).

19. Y. Kim and E. S. Chung, "Fuzzy VIKOR approach for assessing the vulnerability of the water supply to climate change and variability in South Korea," Appl.Math.Model., 37, no. 22, pp. 9419-9430 (2013).

20. S. Nisel, "An Extended VIKOR Method for Ranking Online Graduate Business Programs," Int. J. Inf. Educ. Technol., 4, no. 1, pp. 103-107 (2014).

21. M. F. El-Santawy and A. N. Ahmed, "Evaluating Consulting Firms Using VIKOR," Life Sci. J., 9, no. 4, pp. 5872-5874 (2012).

22. M. F. El-Santawy and A. N. Ahmed, "A VIKOR Approach for Project Selection Problem," Life Sci. J., 9, no. 4, pp. 5878-5880 (2012).

23. A. A. Tangkesalu and J. E. Suseno, "Information System of Performance Assesment on Startup Business using Simple Multi-Attribute Rating Technique Exploiting Ranks (SMARTER)," E3S Web Conf., 73, pp. 2-6 (2018).

24. Y. Dian Harja and R. Sarno, "Determine the best option for nearest medical services using Google maps API, Haversine and TOPSIS algorithm," 2018 Int. Conf. Inf. Commun. Technol. ICOIACT 2018, pp. 814-819, Yogyakarta (2018). 